\title{
Syphilitic Rash in a Non-HIV Female Patient
}

\author{
Naoki Yanagisawa ${ }^{1,2}$
}

Key words: female, skin rash, secondary syphilis

(Intern Med 58: 1799, 2019)

(DOI: 10.2169/internalmedicine.2404-18)

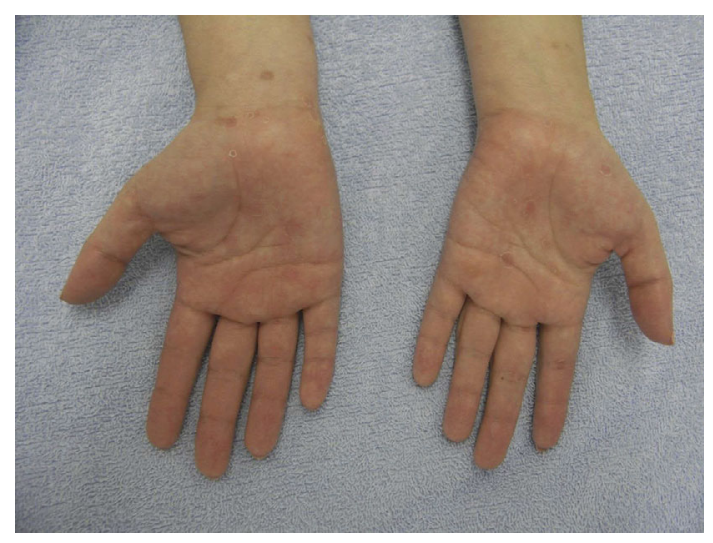

Picture 1.

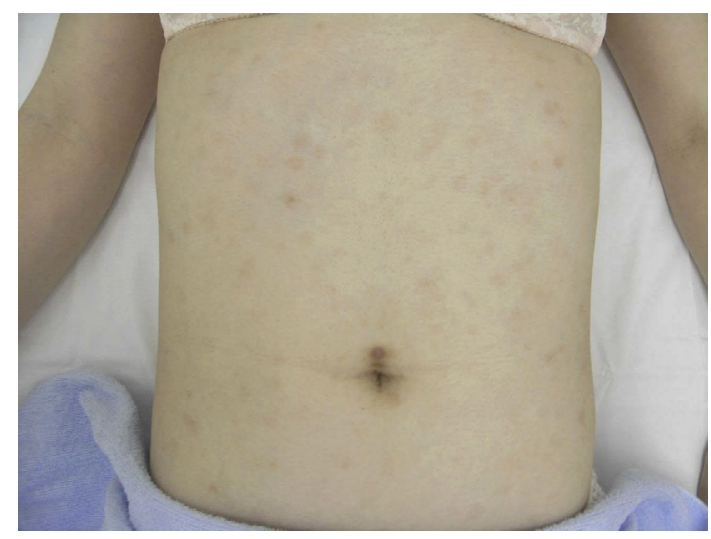

Picture 2.
A 31-year-old woman visited a hospital for the evaluation of a refractory skin rash. She recalled that the rash initially started from her abdomen but now involved her palms and soles. A total of six visits to three different hospitals failed to achieve a definitive diagnosis. An examination showed generalized maculopapular eruption (Picture 1, 2) with no mucocutaneous oral or genital lesions. History-taking revealed that she had started to work as a commercial sex worker three months prior to developing the rash. The rapid plasma reagin (RPR) test and Treponema Pallidum latex agglutination (TPLA) assay were both positive, confirming the diagnosis of syphilis, but negative for HIV. During the clinical course, her male partner also developed a skin rash that was later confirmed to be syphilis. The number of syphilis patients in Japan has sharply increased recently in not only men by women as well $(1,2)$. Physicians should be aware of this typical rash for a rapid diagnosis, as a delay may lead to the spread of the infection as well as an increased risk of congenital syphilis.

The author states that he has no Conflict of Interest (COI).

\section{References}

1. National Institute of Infectious Diseases. Syphilis 2008-2014. Infectious Agents Surveillance Report 36: 17-19, 2015.

2. Takahashi T, Arima Y, Yamagishi T, et al. Rapid increase in reports of syphilis associated with men who have sex with women and women who have sex with men, Japan, 2012 to 2016. Sex Transm Dis 45: 139-143, 2018.

The Internal Medicine is an Open Access journal distributed under the Creative Commons Attribution-NonCommercial-NoDerivatives 4.0 International License. To view the details of this license, please visit (https://creativecommons.org/licenses/ by-nc-nd/4.0/).

\footnotetext{
${ }^{1}$ Bureau of International Health Cooperation, National Center for Global Health and Medicine, Japan and ${ }^{2}$ Department of Environmental Health, Harvard T.H. Chan School of Public Health, USA

Received: November 19, 2018; Accepted: November 29, 2018; Advance Publication by J-STAGE: February 1, 2019

Correspondence to Dr. Naoki Yanagisawa, naokiy-97@umin.ac.jp
}

(C) 2019 The Japanese Society of Internal Medicine. Intern Med 58: 1799, 2019 